\title{
Mechanism underlying the negative inotropic effect in rat left ventricle in hyperthermia: the role of TRPV1
}

\author{
Koji Obata ${ }^{*}$, Hironobu Morita and Miyako Takaki
}

\begin{abstract}
We have previously reported that the negative inotropic effects of hyperthermia $\left(42^{\circ} \mathrm{C}\right)$ on left ventricular (LV) mechanoenergetics using the excised, cross-circulated rat heart model. Here, we investigated the role of TRPV1 on LV mechanoenergetics in hyperthermia. We analyzed the LV end-systolic pressure-volume relation (ESPVR) and the linear relation between the myocardial oxygen consumption per beat $\left(\mathrm{VO}_{2}\right)$ and the systolic pressure-volume area (PVA; a total mechanical energy per beat) during infusion of capsazepine (CPZ) in hyperthermia, or capsaicin (Cap) under 300 bpm pacing. LV ESP decreased in each LV volume and the resultant downward-shift of LV ESPVR was suppressed by CPZ infusion in hyperthermia-hearts. In Cap-treated hearts, LV ESPVR shifted downward from the control ESPVR,

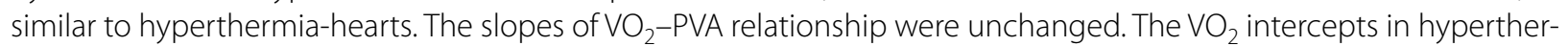
mia-hearts did not decrease because of decreased $\mathrm{E}-\mathrm{C}$ coupling $\mathrm{VO}_{2}$, and inversely increased basal metabolic $\mathrm{VO}_{2}$, which was suppressed by $\mathrm{CPZ}$, though the $\mathrm{VO}_{2}$ intercepts in Cap-treated hearts significantly decreased. The levels of phosphorylated phospholamban at serine 16 decreased significantly in hyperthermia-hearts, as well as Cap-treated hearts. These results indicate that a Cap-induced decrease in the LV contractility, like in cases of hyperthermia, are due to the down-regulation of the total calcium handling in $\mathrm{E}-\mathrm{C}$ coupling, suggesting that negative inotropic effect in hyperthermia-heart is, at least in part, mediated through TRPV1 signaling pathway.
\end{abstract}

Keywords: TRPV1, LV contractility, Excitation-contraction coupling, Oxygen consumption, Hyperthermia

\section{Background}

Myocardial temperature sensitivity affects cardiac contractility following energy metabolism. In addition, the cardiac Troponin I is frequently elevated in patients with heat-related illnesses during a heat wave, which indicates myocardial damage [1]. Others studies, including our own, have previously reported that elevated cardiac temperature decreases left ventricular (LV) contractility and energy consumption, mechanoenergetics, in cardiac muscle strip and hearts isolated from rats, rabbits, or dogs [2-6]. Recently, we have shown that negative inotropic effect in hyperthermia $\left(42{ }^{\circ} \mathrm{C}\right)$ is caused

*Correspondence: obatak@gifu-u.ac.jp

Department of Physiology, Gifu University Graduate School of Medicine,

1-1 Yanagido, Gifu 501-1194, Japan by a decrease in calcium $\left(\mathrm{Ca}^{2+}\right)$ handling in excitationcontraction $(\mathrm{E}-\mathrm{C})$ coupling during which sarcoplasmic reticulum (SR) $\mathrm{Ca}^{2+}$-ATPase (SERCA) activity was suppressed due to phospholamban phosphorylation inhibition [5]. However, it remains unknown how the heart senses the hyperthermia conditions, and transmits the information to signal transduction pathway, which controls LV mechanoenergetics.

Transient receptor potential vanilloid 1 (TRPV1) is a nonselective cation channel that may be activated by a wide variety of exogenous and endogenous physical and chemical stimuli, such as $\mathrm{pH}$, capsaicin (Cap), or temperatures above $43{ }^{\circ} \mathrm{C}\left(109^{\circ} \mathrm{F}\right)$. Capsazepine $(\mathrm{CPZ})$ is a competitive antagonist of TRPV1 which blocks the Capinduced $\mathrm{Ca}^{2+}$ influx in sensory nerves. Cap-sensitive sensory nerves are widely distributed in the cardiovascular 
system, including in the heart, kidneys, and blood vessels [7-9]. Previous studies have reported a cardioprotective role for TRPV1 in myocardial ischemia and reperfusion injury $[9,10]$, in addition to attenuating cardiac hypertrophy $[9,11-14]$. Thus, it is possible that TRPV1 works directly as a sensor for cardiac hyperthermia conditions and controls cardiac contractility and energy metabolism. $\mathrm{Ca}^{2+}$ is also a key player in E-C coupling. SERCA is a $\mathrm{Ca}^{2+}$-ATPase which plays a major role on $\mathrm{Ca}^{2+}$ handling in E-C coupling. We previously reported that elevated cardiac temperature directly induces a negative inotropic action due to suppression of SERCA activity, owing to decreased phosphorylation of phospholamban (PLB) in $\mathrm{Ca}^{2+}$ handling without affecting neuro-, and/ or humoral factors [5]. The increase in SERCA activity is elicited by phosphorylation of PLB at $\operatorname{Ser}^{16}$ by protein kinase A (PKA) and/or $\mathrm{Thr}^{17}$ by calmodulin-dependent protein kinase II (CaMK II) [15]. Previous studies demonstrated that gingerol, a TRPV1 agonists [16], activates $\mathrm{Ca}^{2+}$ pumping in skeletal and cardiac SR and ameliorates diabetes mellitus-induced diastolic dysfunction in isolated myocardium, suggesting that the activation of TRPV1 can increase SERCA activity and improve the diastolic function in hearts $[17,18]$. On the other hand, the LV relaxation also determines the rate of dissociation in cross-bridge cycling and the number of myosin heads interacting with the thin filament (actin) related to myosin ATPase activity. In fact, we have previously shown that the logistic time constant is significantly shortened in hyperthermia [5], which may indicate the acceleration of relaxation by increasing myosin ATPase activity, which related to the increased TRPV1 activity in hyperthermia. Thus, it is possible that TRPV1 agonist or its antagonist exerts cardioprotective effects against damages from heatstroke or severe fevers.

The aim of the present study is to clarify the direct effects of TRPV1 activation on cardiac function and energy metabolism. We investigated the role of TRPV1 in hyperthermia by treatment with CPZ or Cap on LV myocardial mechanoenergetics using the excised, crosscirculated rat heart model to reveal whether TRPV1 acts as molecular micro-thermometers in cardiomyocytes.

\section{Methods}

\section{Experimental animals}

Our investigations were in accordance with the Guide for the Care and Use of Laboratory Animals published by the US National Institutes of Health (NIH Publication No. 85-23, revised 1996), and reviewed and approved by the Animal Research Committee of Gifu University (Gifu, Japan). Three male Wistar rats weighing $464 \pm 57.3 \mathrm{~g}$ were used in each experiment. The largest rat in weight was used as blood supplier. The middle-sized rat was used as metabolic supporter for the excised heart. The smallest rat was used as heart donor in excised cross-circulation rat heart preparation.

\section{Excised cross-circulated rat heart model}

We used the excised, cross-circulated rat heart preparation as previously reported [19-25]; we have also described the same in detail in the Additional file 1: Figure S1.

\section{Data analysis}

We analyzed the obtained data in excised, cross-circulated rat heart preparations as previously reported [1925], and also described it in detail in Additional file 1: Fig. S2A, B.

\section{Analyses of one-beat LV pressure-time curve by logistic function}

We analyzed "logistic" time constant from respective best-fit functions to one-beat LV pressure-time curve at midrange $\mathrm{LV}$ volume (mLVV) during relaxation, with our proposed "logistic function" to evaluate LV end-diastolic relaxation rate or lusitropism [26] at $37{ }^{\circ} \mathrm{C}(n=8-10$ experiments, i.e., excised hearts), $42{ }^{\circ} \mathrm{C} \quad(n=10)$, $42{ }^{\circ} \mathrm{C}+\mathrm{CPZ}(n=10)$, and Cap $(n=8)$.

\section{Experimental protocol}

LV volume (LVV) changes were measured by adjusting the intra-balloon water volume with a syringe in 0.025 $\mathrm{mL}$ steps between $0.08 \mathrm{~mL}$ and $0.23 \mathrm{~mL}$ (5-6 different volumes) (volume-loading run: vol-run) in the presence or absence of $\mathrm{CPZ}$ or Cap at $37{ }^{\circ} \mathrm{C}$ or $42{ }^{\circ} \mathrm{C}$ (Additional file 1: Figure $\mathrm{S} 1$ ). In every vol-run, steady state (where LVP, coronary arteriovenous $\mathrm{O}_{2}$ content difference $\left(\mathrm{AVO}_{2} \mathrm{D}\right)$, and $\mathrm{CBF}$ were stable), was reached $2-3 \mathrm{~min}$ after changing LVV. Cardiac arrest was induced by infusing $\mathrm{KCl}(0.5 \mathrm{~mol} / \mathrm{L})$ into the coronary perfusion tubing at a constant rate $(5-10 \mathrm{~mL} / \mathrm{h})$ with a syringe pump in the presence or absence of $\mathrm{CPZ}$ or Cap at $37{ }^{\circ} \mathrm{C}$ or $42{ }^{\circ} \mathrm{C}$, to measure the basal metabolic $\mathrm{O}_{2}$ consumption. $\mathrm{KCl}$-cardiac arrest was adjusted to abolish electrical excitation while monitoring ventricular electrocardiograms, but not to generate any $\mathrm{KCl}$-induced constrictions of coronary vessels. $\mathrm{VO}_{2}$ and PVA data were obtained by minimal volume loading to avoid volume-loading effects, if any, on $\mathrm{VO}_{2}$ data.

CPZ and Cap were purchased from Wako Pure Chemical Industries, Ltd. (Osaka, Japan). Cap was dissolved as previously reported [27]. CPZ was dissolved in $\mathrm{EtOH}$ at a concentration of $37.7 \mathrm{mg} / \mathrm{mL}$ and was diluted to $377 \mu \mathrm{g} / \mathrm{mL}$ in $1 \% \mathrm{EtOH}$. We confirmed no effect on LV mechanoenergetics with $1 \% \mathrm{EtOH}$ as a vehicle, because final EtOH concentration in blood was 
very low about $0.0002-0.005 \%$. CPZ [final concentration, $1-2 \mu \mathrm{g} / \mathrm{mL}$ (approximately $2-5 \mu \mathrm{M}$ ) at a coronary flow of $2-5 \mathrm{~mL} / \mathrm{min}$ ] was perfused at $5-10 \mu \mathrm{L} / \mathrm{min}$ for 15 min before, for 40-45 min with micro-syringe pump during volume loading (vol)-run and $\mathrm{KCl}$-cardiac arrest (Additional file 1: Figure S1). Cap [final concentration, 20-500 ng/mL (approximately $0.2-4 \mu \mathrm{M}$ ) at a coronary flow of $2-5 \mathrm{~mL} / \mathrm{min}$ ] was perfused at $1-20 \mu \mathrm{L} / \mathrm{min}$ for $15 \mathrm{~min}$ before, for 40-45 min with micro-syringe pump during vol-run, inotropism (ino)-run, and $\mathrm{KCl}$-cardiac arrest (Additional file 1: Figure S1).

All data were measured and sampled at $1 \mathrm{kHz}$ for $5-10 \mathrm{~s}$ and averaged using a PowerLab unit and LabChart software (AD Instruments, Bella Vista, NSW, Australia).

\section{Immunoblotting analysis for PLB, phosphorylated-PLB (p-PLB), and GAPDH}

Immunoblotting analysis was performed as previously reported [5, 21, 28, 29]. In brief, total proteins were purified from the LV free wall of each frozen heart and stored at $-80{ }^{\circ} \mathrm{C}$ after the mechanoenergetic studies. Proteins $(50 \mu \mathrm{g} / \mathrm{lane})$ were separated on a $15 \%$ sodium dodecyl sulfate (SDS)-polyacrylamide gels in a minigel apparatus (Mini-PROTEAN II, Bio-Rad Laboratories, Inc., $\mathrm{CA}$ ) and transferred to polyvinylidene difluoride (PVDF) membranes. The membranes were blocked (4\% Block Ace, Dainippon Pharmaceutical Co., Osaka, Japan) and then incubated with primary antibody against anti-PLB antibody (1:1000 dilution, Upstate Biotechnology, Inc., MA), p-PLB at serine 16 residue ( $\mathrm{p}-\mathrm{PLB}^{\mathrm{Ser} 16}$, Abcam, Cambridge, UK), and $\mathrm{p}$-PLB at threonine 17 residue $\left(\mathrm{p}-\mathrm{PLB}^{\text {Thr17}}\right.$, Badrilla Ltd, Leeds, UK). Detection was performed by the luminescence method (ECL Western blotting detection kit, GE Healthcare Japan, Tokyo, Japan) with peroxidase-linked anti-mouse IgG (1:5000 dilution) or peroxidase-linked anti-rabbit IgG (1:5000). The bands were normalized to anti-GAPDH antibody (Cell Signaling Technology Inc. MA) to confirm equal loading of samples. Band intensity was analyzed with ImageJ/Fiji software.

\section{Statistics}

Multiple comparisons were performed by one-way analysis of variance (ANOVA) with post hoc Bonferroni's test. Alternatively, comparison of unpaired individual values was performed by unpaired $t$ test. A value of $p<0.05$ was considered statistically significant. All data are expressed as the mean \pm S.D.

\section{Results}

Inhibition of hyperthermia-induced negative inotropic effect by $\mathrm{CPZ}$

We previously reported that LV end-systolic pressure (ESP) decreased and thus LV end-systolic pressure-volume relation (ESPVR) shifted downward in hyperthermia conditions at $42{ }^{\circ} \mathrm{C}$ [5]. First, we used a TRPV1 antagonist, CPZ to clarify the role of TRPV1 as a molecular thermometer on negative inotropic effect in hyperthermia-hearts. The LV ESP gradually decreased from 146 to $110 \mathrm{mmHg}$ up to $42{ }^{\circ} \mathrm{C}$ after onset of heating and returned to the original value after heating stopped (Fig. 1a). This ESP decrease was suppressed by the infusion of CPZ (approximately $1.23 \mu \mathrm{g} / \mathrm{mL}$ in blood) (Fig. 1b). The LV end-diastolic pressure (EDP) was maintained during both heating and CPZ-treatment around zero $\mathrm{mmHg}$ (Fig. 1a, b). According to the decrease of LVP in hyperthermia, the $\mathrm{AVO}_{2} \mathrm{D}$ also slightly decreased. The decrease in $\mathrm{AVO}_{2} \mathrm{D}$ was also completely inhibited by $\mathrm{CPZ}$. CBF did not change when the temperature of perfusion blood was increased in the presence or absence of CPZ (Fig. 1). This result indicates that the negative inotropic effect in hyperthermia is inhibited by CPZ, suggesting the possibility for an association with the TRPV1 signaling pathway.

\section{LV mechanoenergetics during CPZ infusion in hyperthermia}

The decrease in ESP at mLVV from 37 to $42^{\circ} \mathrm{C}$ was markedly suppressed by CPZ-treatment in the same heart, though not completely (Fig. 2a). Thus, the decrease of mean ESP at mLVV in hyperthermia-hearts was significantly inhibited by CPZ-treatment (Fig. 3e). We had already reported that the slope and intercept for $\mathrm{VO}_{2}-$ PVA linear relation did not change in hyperthermia conditions, though ESPVR shifted downward from that in normothermia [5]. The $\mathrm{VO}_{2}-\mathrm{PVA}$ data point at $\mathrm{mLVV}$ in a CPZ-treated hyperthermia-heart shifted rightdownward (indicated by a solid square) from that in a hyperthermia-heart (indicated by a solid triangle), which shifted left-downward from that in normothermia (indicated by a solid circle) (Fig. 2b). However, mean slopes and $\mathrm{VO}_{2}$ intercepts for $\mathrm{VO}_{2}-\mathrm{PVA}$ linear relations did not change in CPZ-treated hyperthermia-hearts (Fig. 3a, b). The decrease in mean $\mathrm{VO}_{2}$ for $\mathrm{E}-\mathrm{C}$ coupling and the increase in mean basal metabolic $\mathrm{VO}_{2}$ in hyperthermiahearts, without changing $\mathrm{VO}_{2}$ intercepts, were inhibited by CPZ-treatment (Fig. 3c, d, though not significant in C). The results suggest that CPZ, though not completely, inhibits hyperthermia-induced mechanoenergetics, suggesting that TRPV1 signaling pathway may inhibit the decrease of $\mathrm{VO}_{2}$ for $\mathrm{E}-\mathrm{C}$ coupling and the increase in 


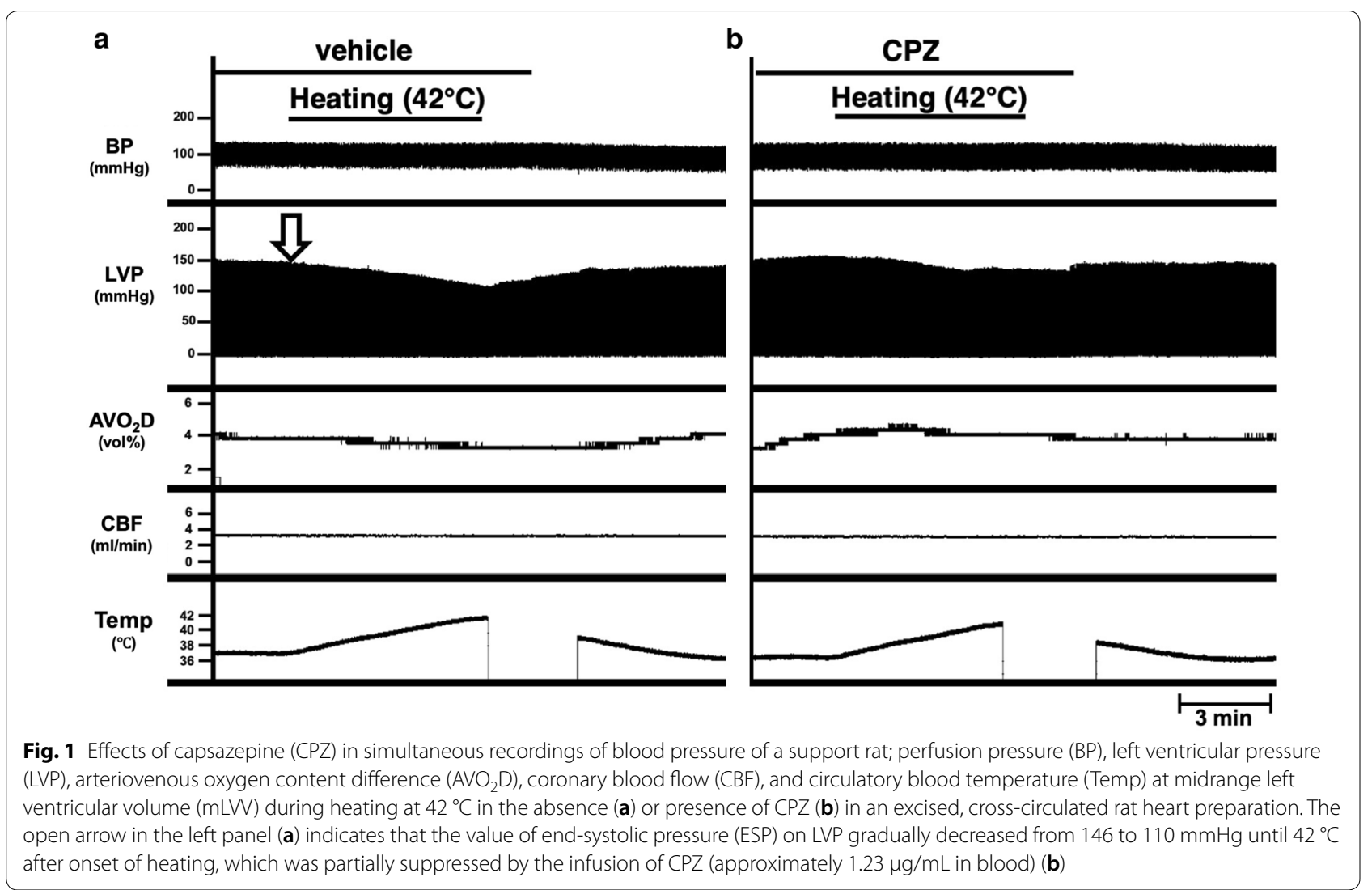

$\mathrm{VO}_{2}$ for basal metabolism in hyperthermia. Mean slope, intercept, $\mathrm{VO}_{2}$ for $\mathrm{E}-\mathrm{C}$ coupling and basal metabolism, LV ESP and CBF at mLVV did not change in CPZ-treated heart at $37^{\circ} \mathrm{C}$ (data not shown).

\section{LV mechanoenergetics during Cap infusion}

An LV ESP-V data point shifted downward in a dosedependent manner during Cap ino-run and, therefore, during Cap vol-run at $10 \mu \mathrm{L} / \mathrm{min}, \mathrm{LV}$ ESPVR shifted downward (Fig. 2c) and mean ESP at mLVVs was significantly lower than that at $37^{\circ} \mathrm{C}$ (Fig. 3e). LV EDPVR remained almost unchanged during the Cap vol-run (Fig. 2c). These results suggest that the hyperthermiainduced negative inotropic action was caused by the Cap-sensitive TRPV1 signaling pathway. The $\mathrm{VO}_{2}-\mathrm{PVA}$ linear relationship during the Cap vol-run shifted downward in parallel, suggesting that the mean $\mathrm{VO}_{2}$ intercept (PVA-independent $\mathrm{VO}_{2}$ ), composed of the $\mathrm{VO}_{2}$ for $\mathrm{E}-\mathrm{C}$ coupling and basal metabolism, decreased significantly in Cap-treated hearts, unlike that in hyperthermia (Figs. 2d, $3 \mathrm{~b})$. The decline in mean $\mathrm{VO}_{2}$ intercept in Cap-treated hearts was caused by the decrease in $\mathrm{VO}_{2}$ consumed in $\mathrm{E}-\mathrm{C}$ coupling without changing basal metabolic $\mathrm{VO}_{2}$ (Fig. 3c, d). The slopes which inversely means the efficiency for converting chemical energy into mechanical work did not alter in Cap-treated hearts like in hyperthermia (Figs. 2a, 3a). The results suggest that the effects of Cap on LV mechanoenergetics were somewhat different from the effects in hyperthermia, although both Cap and hyperthermia exerted negative inotropic effects. CBF did not change in Cap-treated hearts (Fig. 3f).

Immunoblotting of PLB, p-PLB ${ }^{\text {Ser16 }}$, and p-PLB ${ }^{\text {Thr17 }}$ in Capor CPZ-treated hearts in normothermia or hyperthermia The phosphorylation of PLBs, especially p-PLB ${ }^{\text {Thr17 }}$ was remarkably decreased in hyperthermia-hearts, but was unchanged in Cap-treated hearts (Fig. 4a, c). Conversely, mean levels of $\mathrm{p}-\mathrm{PLB}^{\mathrm{Ser} 16}$ decreased significantly in hyperthermic and Cap-treated hearts (Fig. 4a, d). These results indicate that elevated cardiac temperature and Cap-treatment may regulate the phosphorylation (dephosphorylation) of the PLB signaling pathway. Interestingly, reduction in $\mathrm{p}^{-\mathrm{PLB}^{\mathrm{Th} 17}}$ and $\mathrm{p}-\mathrm{PLB}^{\mathrm{Ser} 16}$ in hyperthermic hearts was not inhibited by CPZ-treatment (Fig. 4c, d). The expression levels of PLB protein did not change in Cap-treated hearts at $37{ }^{\circ} \mathrm{C}$ or in $\mathrm{CPZ}$-treated hearts at $37{ }^{\circ} \mathrm{C}$ or $42{ }^{\circ} \mathrm{C}$ (Fig. 4a, b). These results suggest that the decrease in $\mathrm{VO}_{2}$ for $\mathrm{E}-\mathrm{C}$ coupling in both hyperthermic- and 
a

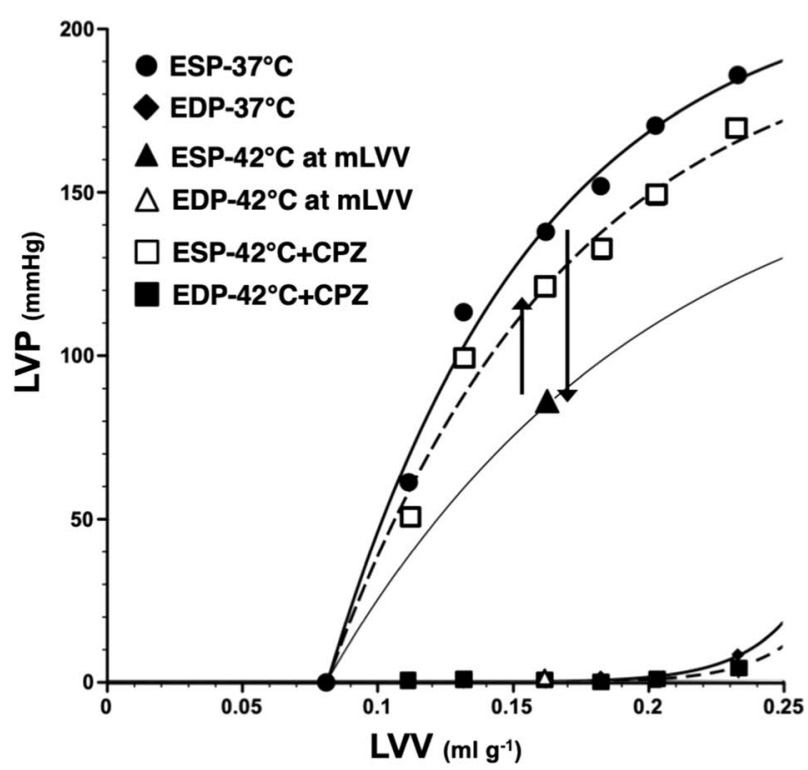

C

ESP-V relation

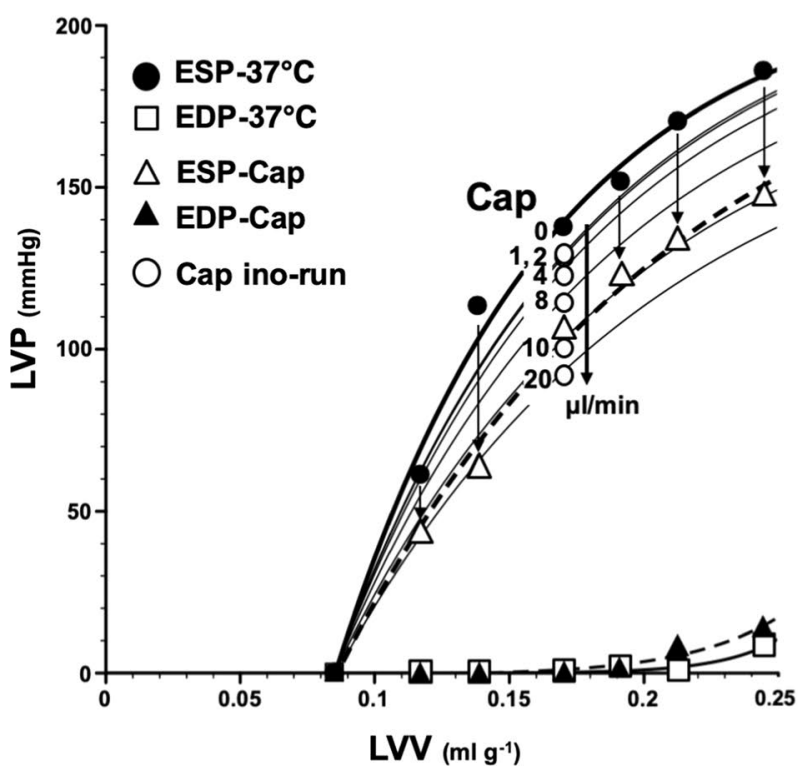

b

$\mathrm{VO}_{2}$-PVA relation

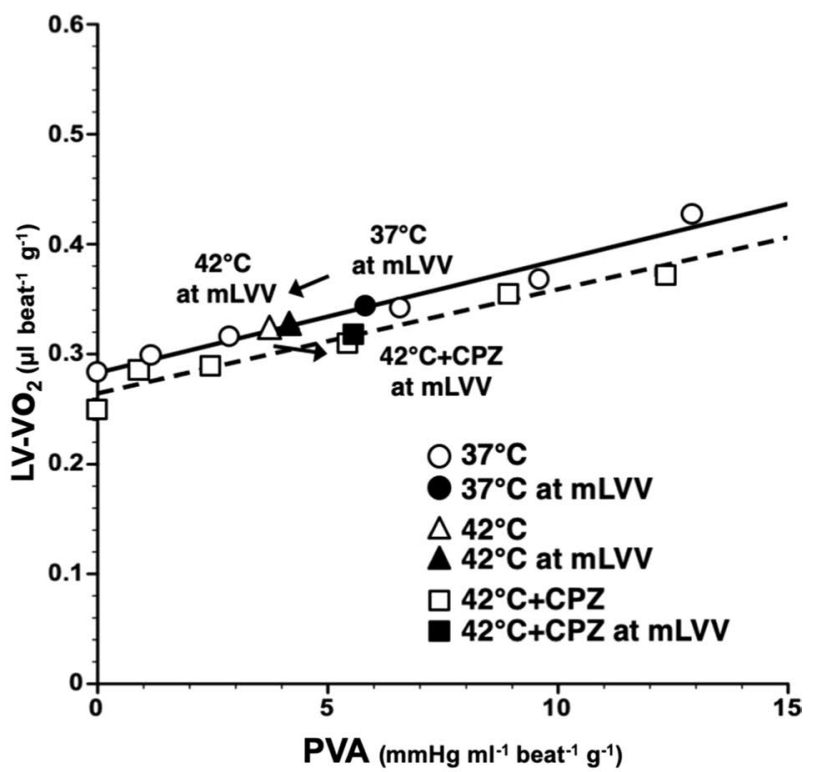

d

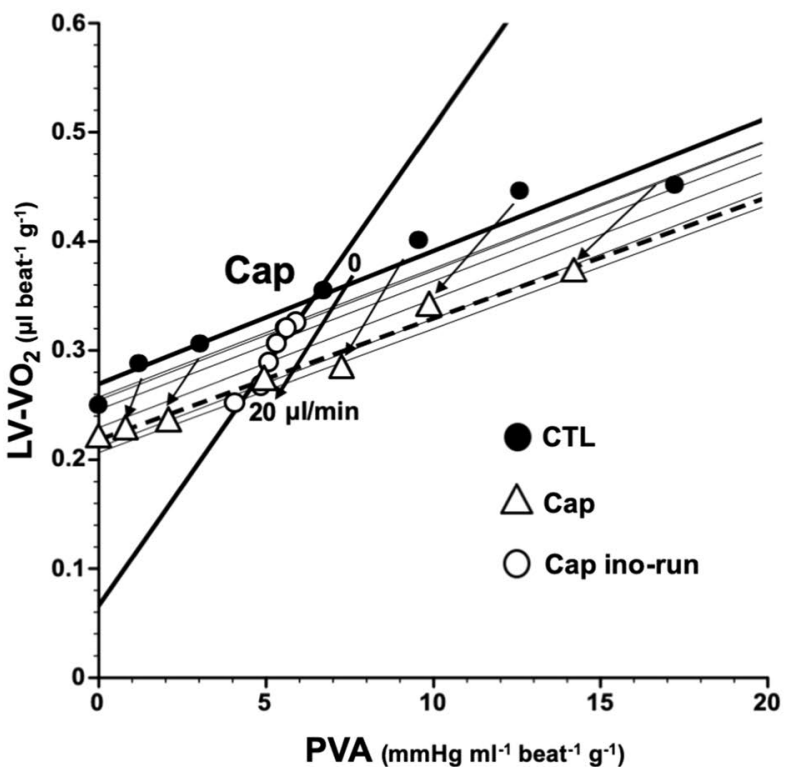

Fig. 2 Representative data of LV end-systolic pressure-volume relation (ESPVR), LV end-diastolic pressure-volume relation (EDPVR), and myocardial oxygen consumption per beat $\left(\mathrm{VO}_{2}\right)$-systolic pressure-volume area (PVA) relation in the presence of $\mathrm{CPZ}\left(1.59 \mu \mathrm{g} / \mathrm{mL}\right.$ in blood) during $42^{\circ} \mathrm{C}(\mathbf{a}$ and b, dotted lines) and in the presence of capsaicin (Cap) $\left(0-461 \mathrm{ng} / \mathrm{mL}\right.$ in blood) at $37^{\circ} \mathrm{C}$ (c and $\mathbf{d}$, dotted lines), respectively. The arrows in panel A indicate that the decrease in LV ESP at $\mathrm{mLVV}$ at $42^{\circ} \mathrm{C}$ (solid triangle) was partially inhibited by CPZ (open square). The fine line indicates the estimated LV ESPVR at $42^{\circ} \mathrm{C}$. Thus, the $\mathrm{VO}_{2}-P V A$ data point at $\mathrm{mLV}$ in CPZ-treated heart at $42^{\circ} \mathrm{C}$ (solid square) shifted right-downward from that in hyperthermia-heart (solid triangle), which left-downward shifted data point from it at $37^{\circ} \mathrm{C}$ (solid circle) (b). On the other hand, the LV ESPVRs in Cap-treated heart shifted downward (c) and each PVA and VO ${ }_{2}$ values (open triangles) at each LV during Cap infusion ( $230 \mathrm{ng} / \mathrm{mL}$ in blood) was smaller than each control value (solid circles), and the $\mathrm{VO}_{2}-\mathrm{PVA}$ linear relations during Cap infusion shifted downward; $\mathrm{VO}_{2}$-intercept values decreased without changes in the slope (d). The open circles indicate that Cap dose-dependently decreased the LV ESP and thus shifted in parallel estimated $\mathrm{VO}_{2}-\mathrm{PVA}$ relation according to stepwise elevation of the Cap infusion rate $(0,1,2,4,6,8,10,20 \mathrm{\mu L} / \mathrm{mL}$ ) with infusion pump (c and $\mathbf{d})$. The fine lines indicate the estimated LV ESPVRs and $\mathrm{VO}_{2}-P V A$ linear relations at various Cap infusion rates $\mathbf{c}$ and $\mathbf{d}$ ) 

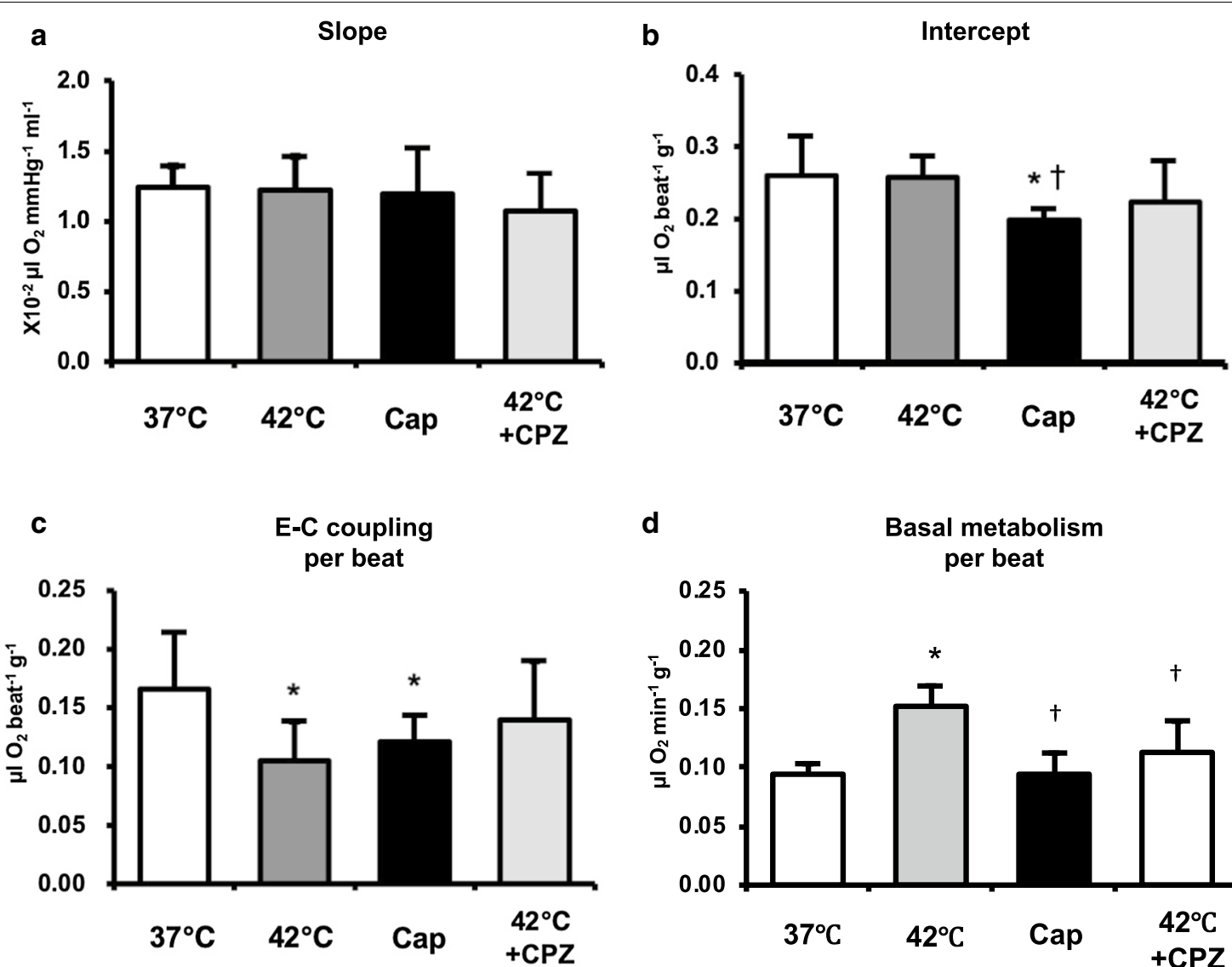

d

Basal metabolism per beat

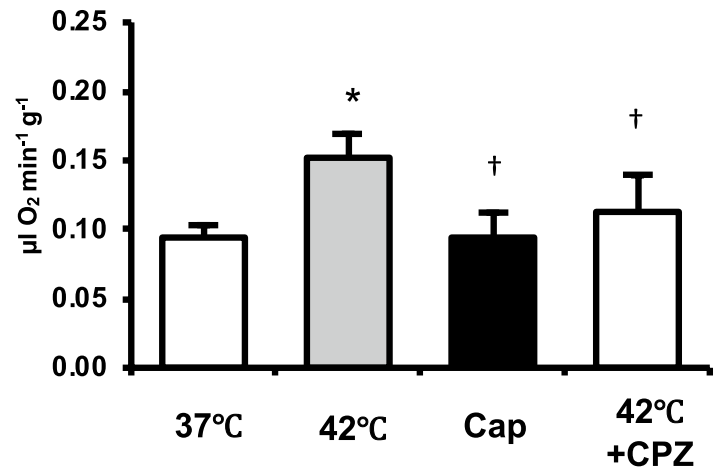

e

ESPmLVV

f

CBF at mLVV
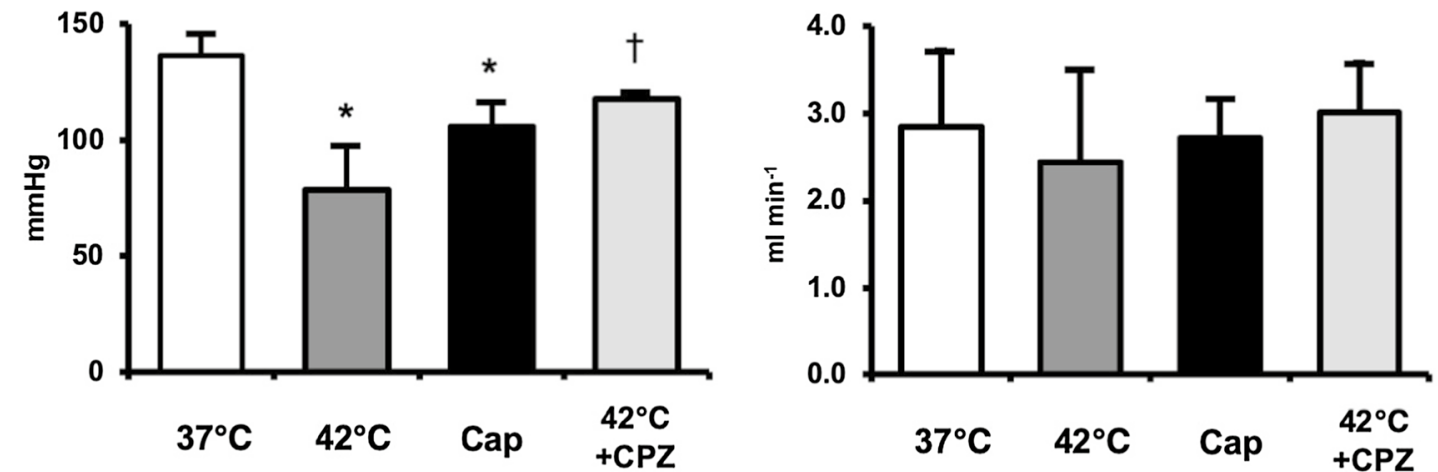

* $P<0.05$ vs. $37^{\circ} \mathrm{C}$

$+P<0.05$ vs. $42{ }^{\circ} \mathrm{C}$

Fig. 3 Comparison of the mean slope (oxygen cost of $\mathrm{PVA}$; $\mathbf{a}$ ), mean $\mathrm{VO}_{2}$ intercept $\left(\mathrm{PVA}\right.$-independent $\mathrm{VO}_{2} ; \mathbf{b}$ ), mean $\mathrm{VO}_{2}$ consumed in $\mathrm{E}-\mathrm{C}$ coupling (c), mean basal metabolic $\mathrm{VO}_{2}(\mathbf{d})$, mean ESP at $\mathrm{mLV}(\mathbf{e})$, and mean CBF at $\mathrm{mLV}(\mathbf{f})$ in the presence or absence of Cap or $\mathrm{CPZ}$ at $37^{\circ} \mathrm{C}$ or $42^{\circ} \mathrm{C}$. Group data are mean \pm SD. ${ }^{*} p<0.05$ vs. $37{ }^{\circ} \mathrm{C},{ }^{+} p<0.05$ vs. $42^{\circ} \mathrm{C}$. The mean slope and mean CBF did not change in Cap- or CPZ-treated hearts during $37^{\circ} \mathrm{C}$ or $42^{\circ} \mathrm{C}(\mathbf{a}, \mathbf{f})$. The mean $\mathrm{VO}_{2}$ intercepts in Cap-treated hearts were significantly lower than that at $37^{\circ} \mathrm{C}(\mathbf{b})$, which was due to the decrease in mean $\mathrm{VO}_{2}$ consumed in $\mathrm{E}-\mathrm{C}$ coupling (c) without changing mean basal metabolic $\mathrm{VO}_{2}$ (d). The decrease in the mean $\mathrm{VO}_{2}$ for $\mathrm{E}-\mathrm{C}$ coupling and the increase of mean basal metabolic $\mathrm{VO}_{2}$ in hyperthermia-hearts without changing mean $\mathrm{VO}_{2}$ intercepts was inhibited by CPZ-treatment (c, $\mathbf{d}$ ). The mean ESP at mLV in hyperthermia- and Cap-treated hearts were significantly lower than that during $37^{\circ} \mathrm{C}(\mathbf{e})$. The decrease of mean ESP at $\mathrm{mLV}$ in hyperthermia-hearts significantly inhibited by CPZ-treatment (e) 


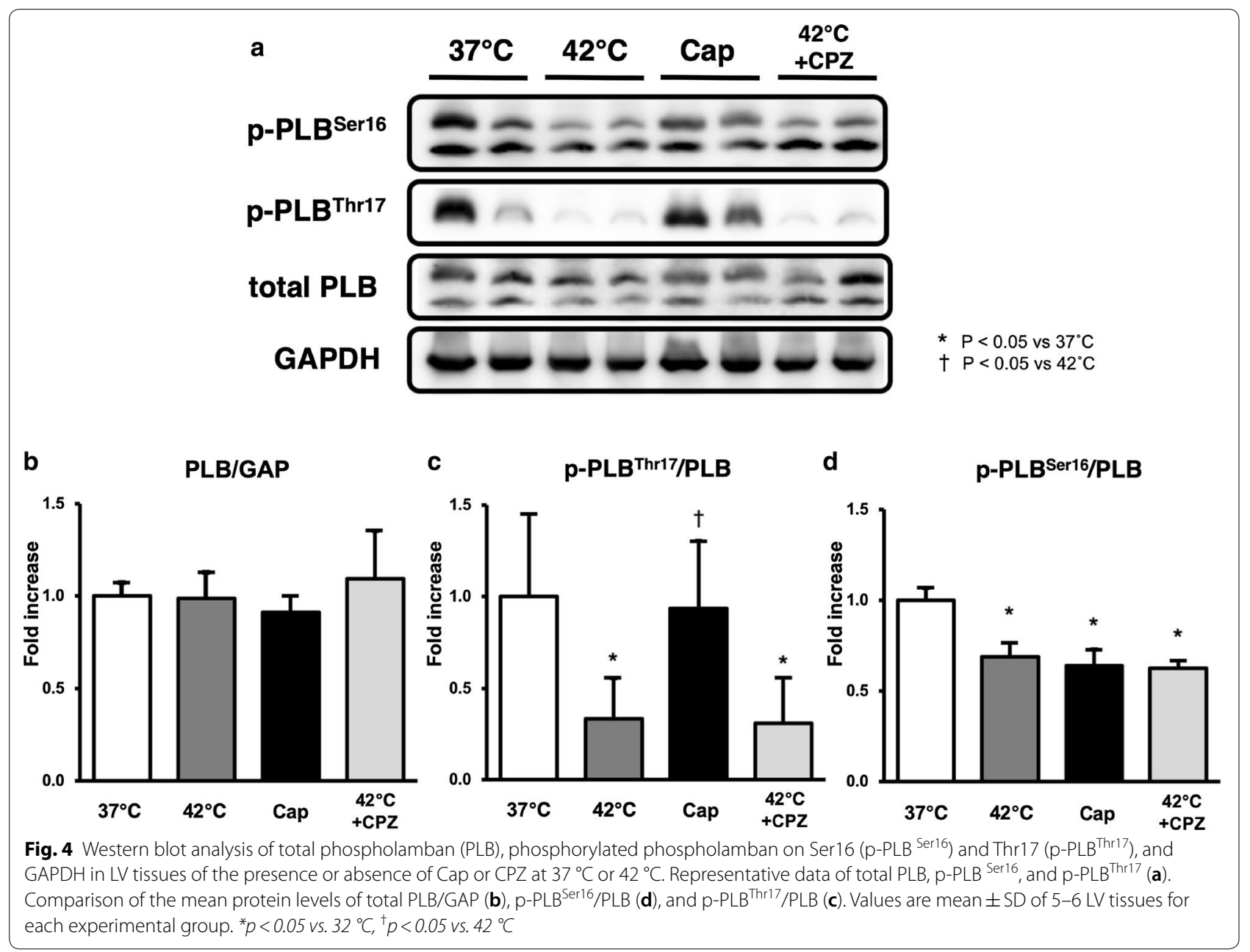

Cap-treated hearts is induced by a reduction in SERCA activity, which occurs as a result of decreased p-PLB.

\section{Logistic time constants during Cap in normothermia and CPZ in hyperthermia}

Mean duration of LV relaxation time significantly decreased in hyperthermia-hearts, but did not change in Cap-treated hearts (Fig. 5c, f). This decrease in hyperthermia is associated with temperature-dependent myosin ATPase activity in cross-bridge cycling, whereas Cap is not likely to act on it directly. The decrease in LV relaxation time in hyperthermia was partially inhibited in the CPZ-treated hearts (Fig. 5f). These results suggest that cross-bridge dissociation and/or the acceleration of intracellular $\mathrm{Ca}^{2+}$ uptake in SR through SERCA2a is sped-up via the TRPV1 signaling pathway.

\section{Discussion}

In the present study, we demonstrated that the TRPV1 antagonist, CPZ, inhibits the negative inotropic action in hyperthermia-hearts. We also show that the TRPV1 agonist, Cap also induces negative inotropic effects with the decrease of $\mathrm{VO}_{2}$ for $\mathrm{E}-\mathrm{C}$ coupling like in hyperthermia-hearts. Mechanoenergetic analysis revealed that the $\mathrm{VO}_{2}-\mathrm{PVA}$ slopes were not significantly different in hyperthermia-, CPZ-treated hyperthermia-, or Cap-treated hearts. The $\mathrm{VO}_{2}$ intercept of the $\mathrm{VO}_{2}-\mathrm{PVA}$ linear relation did not change in CPZ-treated hyperthermia-hearts, but the $\mathrm{VO}_{2}$ intercept in Cap-treated hearts decreased due to the decrease in $\mathrm{VO}_{2}$ for $\mathrm{E}-\mathrm{C}$ coupling. $\mathrm{E}-\mathrm{C}$ coupling $\mathrm{VO}_{2}$ decreased and basal metabolic $\mathrm{VO}_{2}$ increased in hyperthermia-hearts; however, the $\mathrm{E}-\mathrm{C}$ coupling $\mathrm{VO}_{2}$ tended to increase and the basal metabolic $\mathrm{VO}_{2}$ significantly decreased in the CPZ-treated hyperthermia-hearts compared to hyperthermia-hearts. 


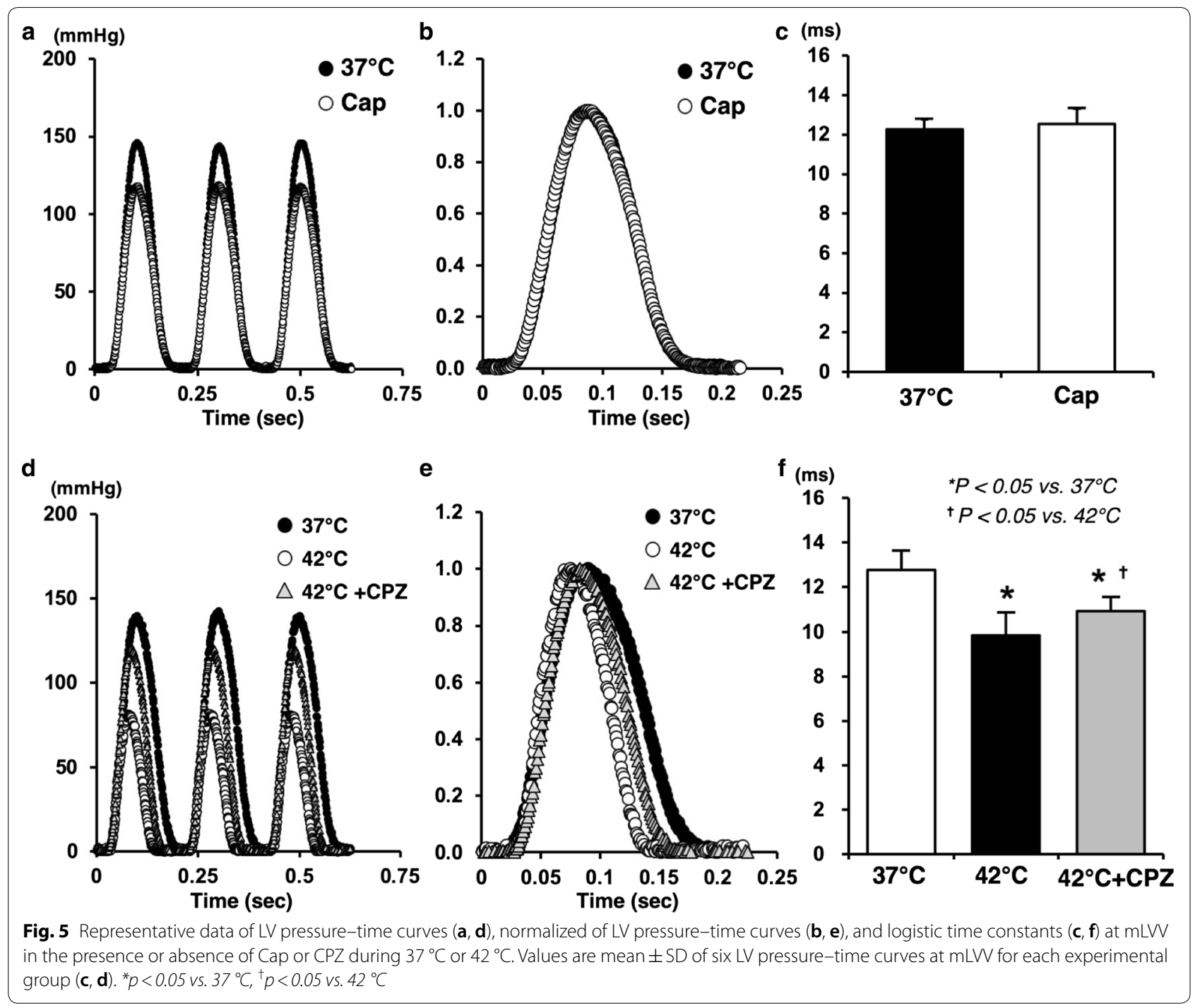

Western blotting analysis revealed that the ratio of p-PLB ${ }^{\text {Ser16/PLB }}$ significantly decreased in both hyperthermia- and Cap-treated hearts, but the ratio of $\mathrm{p}-P L B^{\text {Thr17}} / \mathrm{PLB}$ remarkably decreased only in hyperthermia-hearts. Thus, we considered that the negative inotropic effects in hyperthermia-hearts could be caused by a decrease in $\mathrm{Ca}^{2+}$ handling due, at least in part, to Capand/or CPZ-sensitive TRPV1 signaling.

First, we examined whether the administration of the TRPV1 antagonist, CPZ, can inhibit the negative inotropism in hyperthermia-hearts using the excised, cross-circulated rat heart model (Additional file 1: Figure S1). As a result, CPZ suppressed the decrease of LV ESP in hyperthermia-heart (Figs. 1, 2a). These results astonished us, because previous studies reported that $\mathrm{CPZ}$ does not block acid- or heat-induced activation of TRPV1 in sensory nerves [30,31]. Therefore, the inhibition of negative inotropism in CPZ-treated hyperthermia-hearts may be caused by blocking of other TRPV1 subtypes, or by the non-selective action of CPZ. We also found that the TRPV1 agonist, Cap, also shifted the LV ESPVR downward in a dose-dependent manner (Fig. 2c). Therefore, we considered that the negative inotropic effects in hyperthermia-hearts may be mediated through the TRPV1 signaling pathway. In fact, we previously reported that high-dose Cap induces negative inotropic effects on cardiac muscles [27].

TRPV1 is located on the cardiac sensory nerves and might function as a molecular sensor to detect tissue ischemia and activate cardiac nociceptors because a selective antagonist of TRPV1, iodoresiniferatoxin attenuates both bradykinin- and ischemia-induced firing of cardiac spinal afferent nerves [32, 33]. In contrast, Andrei et al. demonstrated that TRPV1 is functionally expressed 
in cardiac myocytes of adult mice and co-localizes at z-discs, costameres and intercalated discs [34]. Hurt et al. showed that TRPV1 localizes in the mitochondria of primary neonatal cardiomyocytes [10]. Therefore, TRPV1 in cardiomyocytes may have several subtypes and the roles that they may play is still up for debate. In the present study, we used the excised, cross-circulated rat heart model, which is a suitable for evaluating the direct effects of TRPV1 agonists or antagonists in hearts (cardiomyocytes).

The $\mathrm{VO}_{2}-\mathrm{PVA}$ slopes were not significantly different among hyperthermia-, hyperthermia CPZ-treated, or Cap-treated hearts, which means that the oxygen cost of PVA (i.e., the efficiency of chemo-mechanical energy transduction), was maintained regardless of the status of TRPV1 in the excised rat hearts. These results are consistent with previous observation in hyperthermia rat hearts [5], and Cap-treated or hyperthermia canine hearts $[4,6,27]$.

We have previously shown that the $\mathrm{VO}_{2}$ intercept in hyperthermia-hearts did not change because of the decreased $\mathrm{VO}_{2}$ for $\mathrm{E}-\mathrm{C}$ coupling and reversely increased basal metabolic $\mathrm{VO}_{2}$ [5]. We found that the $\mathrm{VO}_{2}$ intercept did not change in CPZ-treated hyperthermia hearts (Figs. 2b, 3b). However, the decrease in E-C coupling $\mathrm{VO}_{2}$ and the increase in the basal metabolic $\mathrm{VO}_{2}$ were significantly inhibited in CPZ-treated hyperthermia hearts (see Fig. 3c, d). However, the $\mathrm{VO}_{2}$ intercept decreased in Cap-treated hearts due to a decrease in $\mathrm{VO}_{2}$ for $\mathrm{E}-\mathrm{C}$ coupling (Figs. 2d, 3b-d). Therefore, both hyperthermia and Cap-treatment can induce the decrease of $\mathrm{VO}_{2}$ for $\mathrm{E}-\mathrm{C}$ coupling, which may be mediated by the activation of TRPV1 in cardiomyocytes. However, CPZ predominantly suppressed the increase of the basal metabolic $\mathrm{VO}_{2}$ in hyperthermia-hearts but Cap did not increase the basal metabolic $\mathrm{VO}_{2}$, unlike in hyperthermia-hearts. This means that the $\mathrm{VO}_{2}$ for basal metabolism may be affected by a hyperthermia- and CPZ-sensitive TRPV1, which is different from a Cap-sensitive TRPV1.

The $\mathrm{VO}_{2}$ for $\mathrm{E}-\mathrm{C}$ coupling mainly means the energy consumption by SERCA2a for SR $\mathrm{Ca}^{2+}$ uptake in cardiomyocytes. SERCA2a plays a crucial role in diastolic function in heart. In the present study, the decrease of $\mathrm{VO}_{2}$ for E-C coupling in both hyperthermia- or Cap-treated hearts might be caused by a decline of amplitude in transient $\mathrm{Ca}^{2+}$, resulting in the negative inotropic effect. Previous studies reported that the amplitude of transient $\mathrm{Ca}^{2+}$ was significantly decreased by increasing temperatures from 37 to $40{ }^{\circ} \mathrm{C}$ in vitro in embryonic chick hearts [35]. However, the force development decreased under hyperthermic conditions $\left(42{ }^{\circ} \mathrm{C}\right)$, with unchanged intracellular transient $\mathrm{Ca}^{2+}$ using rat isolated cardiac trabeculae [3]. It was concluded that the $\mathrm{Ca}^{2+}$ kinetics was accelerated, as a result, the time for myofilament activation reduced under hyperthermia.

Interestingly, the logistic time constant significantly shortened in hyperthermia, which was partially suppressed by CPZ-treatment, but remained unchanged by Cap-treatment (Fig. 5). Therefore, the effect of Cap or hyperthermia on the LV lusitropy was not similar despite both having negative inotropic effects. Thus, LV lusitropy might be, at least in part, mediated through TRPV1 signaling because CPZ partially inhibited the shortening of logistic time constant during hyperthermia. We previously reported that a possible mechanism for the negative inotropic effect in hyperthermic hearts could be considered to accelerate the rate of detachment in cross-bridge cycling and/or decreasing the number of myosin heads interacting with the thin filament (actin) due to increased myosin ATPase activity [5]. Myosin and actin interaction (i.e., cross-bridge cycling) might not be affected by a Cap-sensitive TRPV1 signaling pathway because Cap did not change the logistic time constant. Thus, the activity of myosin ATPase might be mainly dependent on temperature condition. The inhibition of shortened logistic time constant by CPZ might be caused by the decreased $\mathrm{Ca}^{2+}$ handling in $\mathrm{E}-\mathrm{C}$ coupling rather than myosin and actin interaction. These results suggest that the negative inotropic action in Cap-treated hearts might be induced by a decrease in $\mathrm{VO}_{2}$ for $\mathrm{E}-\mathrm{C}$ coupling as well as by the decline in amplitude in transient $\mathrm{Ca}^{2+}$ through TRPV1 signaling pathway. However, the LV diastolic function may be at least in part mediated through a hyperthermia- and CPZ-sensitive TRPV1, but may not be affected by a Cap-sensitive TRPV1. The $\mathrm{VO}_{2}$ for basal metabolism might be related to the different effects of TRPV1 in mitochondria of cardiomyocytes.

Phosphorylation of PLB (p-PLB) at either Ser ${ }^{16}$ by PKA, or $\mathrm{Thr}^{17}$ by CaMK II elevates SERCA activity (i.e., the acceleration of intracellular $\mathrm{Ca}^{2+}$ uptake to the SR) [15]. Therefore, the down-regulation of p-PLB (Fig. 4) indicates a decline in SERCA activity, which was supported by the decrease in $\mathrm{VO}_{2}$ for $\mathrm{E}-\mathrm{C}$ coupling in both hyperthermic and Cap-treated hearts. The phosphorylation of PLB is the main determinant of $\beta 1$-adrenergic responses. Although phosphorylation of $\mathrm{Thr}^{17}$ by CaMKII contributes to this effect, its role is subordinate to that of the PKA-dependent increase in cytosolic $\mathrm{Ca}^{2+}$ that is necessary to activate CaMKII [36]. Therefore, phosphorylation at $\mathrm{Ser}^{16}$ precedes that of $\mathrm{Thr}^{17}$ in hearts. A shift from p-PLB ${ }^{\text {Ser16 }}$ to $\mathrm{p}-\mathrm{PLB}^{\text {Thr17 }}$ was observed under prolonged $\beta 1$-adrenergic stimulation [37].

Here we demonstrate that the ratio of $\mathrm{p}-\mathrm{PLB}^{\mathrm{Thr} 17}$ / PLB decreases significantly in hyperthermic heartsunlike in Cap-treated hearts - and that the ratio of

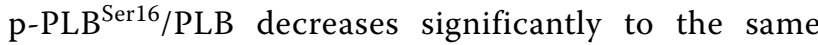


degree in both the hyperthermia and Cap-treated hearts. Interestingly, CPZ did not suppress reduction in $\mathrm{p}-\mathrm{PLB}^{\mathrm{Thr} 17}$ and $\mathrm{p}-\mathrm{PLB}^{\mathrm{Ser} 16}$ (Fig. 4). These results suggest that the decrease in $\mathrm{p}-\mathrm{PLB}^{\mathrm{Ser} 16}$ represents the down-regulation of PKA activity in both hyperthermic and Cap-treated hearts, and that the decrease in $\mathrm{PLB}^{\text {Thr17 }}$ represents the down-regulation of CaMKII activity only in the hyperthermic hearts, which may be independent of a CPZ-sensitive signaling pathway. The inhibitory mechanisms of PKA and/or CaMKII via TRPV1 are unclear, but previous studies have reported a cardioprotective role for TRPV1 in myocardial ischemia and reperfusion injury $[9,10]$. CaMKIIdependent phosphorylation of PLB has been linked to protective effects in both acidosis and ischemia/reperfusion [38]. Hyperthermia-sensitive TRPV1, but not Cap- and CPZ-sensitive TRPV1 may protect against myocardial acidosis and ischemia/reperfusion injury via CaMKII signaling pathway. Phosphorylation of PLB is also dependent on the activity of the type 1 phosphatase (PP1). Dephosphorylation of PLB reverses the activation of SERCA2a [39]. The PP1 activity is controlled by several kinases and phosphatases. TRPV1, but not CPZ-sensitive TRPV1, may contribute to activate these signaling pathways. Further investigation is needed to clarify the questions.

Although CPZ significantly inhibited the negative inotropic effect during hyperthermia, CPZ partially improved the decrease in $\mathrm{VO}_{2}$ for $\mathrm{E}-\mathrm{C}$ coupling and did not improve the decrease in p-PLBs. The results suggest that $\mathrm{CPZ}$ did not completely recover $\mathrm{Ca}^{2+}$ handling in E-C coupling including SERCA2a activity. On the other hand, CPZ inhibited the shortening of the logistic time constant during hyperthermia despite no shortening of that during Cap-treatment. The reason is uncertain, but studies have reported that TRPV1 expressed in mouse skeletal muscle presents only at the SR membrane and functions as an SR $\mathrm{Ca}^{2+}$ leak channel [40]. Previous studies also reported that TRPV1 localizes at the $\mathrm{z}$-discs, costameres, and intercalated discs [34] or at the mitochondria in cardiomyocytes [10]. Therefore, we hypothesize that a hyperthermia-sensitive, a Cap-sensitive, or a CPZsensitive TRPV1 subtypes may exist in cardiomyocytes and that these subtypes may have different localizations and functions. In fact, previous studies demonstrated that the pharmacological actions of capsaicin are elicited via TRPV1-independent mechanisms in many organs or cells except for heart (cardiomyocytes) [41-46]. Therefore, the present study would be the first to show the evidence for the TRPV1-independent action of capsaicin in cardiac mechanoenergetics.

\section{Conclusion}

In conclusion, we have provided evidence that in hyperthermia-hearts TRPV1 plays an important role in negative inotropic action using the excised, cross-circulated rat heart model. CPZ inhibited the negative inotropic effects by improving $\mathrm{Ca}^{2+}$ handling and basal metabolism in hyperthermia-hearts. Both hyperthermia and Cap induced the negative inotropic action, which may relate to the decrease of SERCA activity due to the decline of p-PLB via TRPV1 signaling pathway. In clinical implication, we expect TRPV1 antagonists including CPZ may also exert cardioprotective effects against damages from heatstroke or severe fevers due to the inhibition of negative inotropism in hyperthermia conditions. We conclude that hyperthermia-induced negative inotropic action is mediated via TRPV1 which acts as a molecular micro-thermometer.

\section{Supplementary information}

Supplementary information accompanies this paper at https://doi. org/10.1186/s12576-020-00734-5.

Additional file 1. Supplemental methods for the excised cross-circulated rat heart model and the data analysis. Figure S1. Schematic illustration of experimental setting for the excised blood-perfused rat heart. Figure S2. Schematic illustration of framework of ESPVR-VO2-PVA.

\section{Abbreviations}

LV: Left ventricular; TRPV: Transient receptor potential vanilloid; ESP: Endsystolic pressure; EDP: End-diastolic pressure; ESPVR: ESP-volume relation; EDPVR: EDP-volume relation; $\mathrm{VO}_{2}$ : Myocardial oxygen consumption per beat; PVA: Pressure-volume area; Bpm: Beats per minute; CPZ: Capsazepine; Cap: Capsaicin; E-C: Excitation-contraction; PLB: Phospholamban; SR: Sarcoplasmic reticulum; PKA: Protein kinase A; CaMK II: Calmodulin-dependent protein kinase Il; $\mathrm{mLVV}$ : Midrange LV volume; $\mathrm{AVO}_{2} \mathrm{D}$ : Arteriovenous $\mathrm{O}_{2}$ content difference; CBF: Coronary blood flow.

\section{Acknowledgements}

We would like to thank Editage (http://www.editage.jp) for English language editing.

\section{Authors' contributions}

$\mathrm{KO}$ conducted experiments and obtained the data. HM and MT supervised the present study. $\mathrm{KO}$ and MT performed the data analysis and drafted the manuscript. All authors read and approved the final manuscript.

\section{Funding}

This work was supported by Grants-in-aid No. 25460283 and 18K11125 for Scientific Research from the Ministry of Education, Culture, Sports, Science and Technology of Japan, and Research grants from The Tojuro lijima Foundation for Food Science and Technology and The NOVARTIS Foundation (Japan) for the Promotion of Science to K.O.

\section{Availability of data and materials}

The datasets used and/or analyzed during the current study are available from the corresponding author on reasonable request.

\section{Ethics approval and consent to participate}

All experimental procedures were approved by the Animal Research Committee of Gifu University (Gifu, Japan) and were in accordance with the guiding principles for care and use of animals in the field of physiological sciences outlined by the Physiological Society of Japan. 


\section{Consent for publication}

No applicable.

\section{Competing interests}

The authors declare that they have no competing interests.

Received: 8 August 2019 Accepted: 9 December 2019

Published online: 05 February 2020

\section{References}

1. Hausfater P, Doumenc B, Chopin S, Le Manach Y, Santin A, Dautheville S, Patzak A, Hericord P, Mégarbane B, Andronikof M, Terbaoui N, Riou B (2010) Elevation of cardiac troponin I during non-exertional heat-related illnesses in the context of a heat wave. Crit Care 14(3):R99. https://doi. org/10.1186/cc9034

2. Goto Y, Slinker BK, LeWinter MM (1991) Effect of coronary hyperemia on Emax and oxygen consumption in blood-perfused rabbit hearts Energetic consequences of Gregg's phenomenon. Circ Res 68(2):482-492

3. Hiranandani N, Varian KD, Monasky MM, Janssen PM (2006) Frequencydependent contractile response of isolated cardiac trabeculae under hypo-, normo-, and hyperthermia conditions. J Appl Physiol 100:17271732. https://doi.org/10.1152/japplphysiol.01244.2005

4. Mikane T, Araki J, Suzuki S, Mizuno J, Shimizu J, Mohri S, Matsubara H, Hirakawa M, Ohe T, Suga $\mathrm{H}$ (1999) $\mathrm{O}_{2}$ cost of contractility but not of mechanical energy increases with temperature in canine left ventricle. Am J Physiol Heart Circ Physiol 277:H65-H73. https://doi.org/10.1152/ ajpheart.1999.277.1.H65

5. Obata K, Takeshita D, Morita H, Takaki M (2018) Left ventricular mechanoenergetics in excised, cross-circulated rat hearts under hypo-, normo-, and hyperthermia conditions. Sci Rep 8(1):16246. https://doi.org/10.1038/ s41598-018-34666-3

6. Saeki A, Goto Y, Hata K, Takasago T, Nishioka T, Suga H (2000) Negative inotropism of hyperthermia increases oxygen cost of contractility in canine hearts. Am J Physiol Heart Circ Physiol 279:H2855-H2864. https:// doi.org/10.1152/ajpheart.2000.279.6.H2855

7. Barja F, Mathison R, Huggel H (1983) Substance P-containing nerve fibers in large peripheral blood vessels of the rat. Cell Tissue Res 229:411-422

8. Wharton J, Gulbenkian S, Mulderry PK, Ghatei MA, McGregor GP, Bloom SR, Polak JM (1986) Capsaicin induces a depletion of calcitonin generelated peptide (CGRP)-immunoreactive nerves in the cardiovascular system of the guinea pig and rat. J Auton Nerv Syst 16:289-309. https:// doi.org/10.1016/0165-1838(86)90035-4

9. Yue Z, Xie J, Yu AS, Stock J, Du J, Yue L (2015) Role of TRP channels in the cardiovascular system. Am J Physiol Heart Circ Physiol 308(3):H157-H182. https://doi.org/10.1152/ajpheart.00457.2014

10. Hurt CM, Lu Y, Stary CM, Piplani H, Small BA, Urban TJ, Qvit N, Gross GJ, Mochly-Rosen D, Gross ER (2016) Transient receptor potential vanilloid 1 regulates mitochondrial membrane potential and myocardial reperfusion injury. J Am Heart Assoc. 5(9):003774. https://doi.org/10.1161/ JAHA.116.003774

11. Buckley CL, Stokes AJ (2011) Mice lacking functional TRPV1 are protected from pressure overload cardiac hypertrophy. Channels 5:367-374. https:// doi.org/10.4161/chan.5.4.17083

12. Gao F, Liang Y, Wang X, Lu Z, Li L, Zhu S, Liu D, Yan Z, Zhu Z (2014) TRPV1 activation attenuates high-salt diet-induced cardiac hypertrophy and fibrosis through PPAR-d upregulation. PPAR Res. https://doi. org/10.1155/2014/491963

13. Lang H, Li Q, Yu H, Li P, Lu Z, Xiong S, Yang T, Zhao Y, Huang X, Gao P, Zhang H, Shang Q, Liu D, Zhu Z (2015) Activation of TRPV1 attenuates high salt-induced cardiac hypertrophy through improvement of mitochondrial function. Br J Pharmacol 172(23):5548-5558. https://doi. org/10.1111/bph.12987

14. Wang Q, Ma S, Li D, Zhang Y, Tang B, Qui C, Yang Y, Yang D (2014) Dietary capsaicin ameliorates pressure overload induced cardiac hypertrophy and fibrosis through the transient receptor potential vanilloid type 1. Am J Hypertens 27:1521-1529. https://doi.org/10.1093/ajh/hpu068

15. Mattiazzi A, Mundiña-Weilenmann C, Guoxiang C, Vittone L, Kranias E (2005) Role of phospholamban phosphorylation on Thr17 in cardiac physiological and pathological conditions. Cardiovasc Res 68(3):366-375. https://doi.org/10.1016/j.cardiores.2005.08.010

16. Dedov VN, Tran VH, Duke CC, Connor M, Christie MJ, Mandadi S, Roufogalis BD (2002) Gingerols: a novel class of vanilloid receptor (VR1) agonists. Br J Pharmacol 137(6):793-798. https://doi.org/10.1038/sj.bjp.0704925

17. Kobayashi M, Shoji N, Ohizumi Y (1987) Gingerol, a novel cardiotonic agent, activates the $\mathrm{Ca}^{2+}$-pumping ATPase in skeletal and cardiac sarcoplasmic reticulum. Biochim Biophys Acta 903(1):96-102. https://doi. org/10.1016/0005-2736(87)90159-3

18. Namekata I, Hamaguchi S, Wakasugi Y, Ohhara M, Hirota Y, Tanaka H (2013) Ellagic acid and gingerol, activators of the sarco-endoplasmic reticulum $\mathrm{Ca}^{2+}$-ATPase, ameliorate diabetes mellitus-induced diastolic dysfunction in isolated murine ventricular myocardia. Eur J Pharmacol 706(1-3):48-55. https://doi.org/10.1016/j.ejphar.2013.02.045

19. Hata Y, Sakamoto T, Hosogi S, Ohe T, Suga H, Takaki M (1998) Effects of thapsigargin and $\mathrm{KCl}$ on the $\mathrm{O}_{2}$ use of the excised blood-perfused rat heart. J Mol Cell Cardiol 30(10):2137-2143. https://doi.org/10.1006/ jmcc.1998.0766

20. Hata Y, Sakamoto T, Hosogi S, Ohe T, Suga H, Takaki M (1998) Linear O use-pressure-volume area relation from curved end-systolic pressurevolume relation of the blood-perfused rat left ventricle. Jpn J Physiol 48(3):197-204. https://doi.org/10.2170/jjphysiol.48.197

21. Mitsuyama S, Takeshita D, Obata K, Zhang GX, Takaki M (2013) Left ventricular mechanical and energetic changes in long-term isoproterenolinduced hypertrophied hearts of SERCA2a transgenic rats. J Mol Cell Cardiol 59:95-106. https://doi.org/10.1016/j.yjmcc.2013.02.012

22. Obata K, Takaki M (2018) Methods for the preparation of an excised cross-circulated rat heart. Methods Mol Biol 1816:117-132. https://doi. org/10.1007/978-1-4939-8597-5_9

23. Takaki M (2004) Left ventricular mechanoenergetics in small animal. Jpn J Physiol 54:175-207. https://doi.org/10.2170/jjphysiol.54.175

24. Tsuji T, Ohga Y, Yoshikawa Y, Sakata S, Abe T, Tabayashi N, Kobayashi S, Kitamura S, Taniguchi S, Suga H, Takaki M (2001) Rat cardiac contractile dysfunction induced by $\mathrm{Ca}^{2+}$ overload: possible link to the proteolysis of fodrin. Am J Physiol Heart Circ Physiol 281:H1286-H1294. https://doi. org/10.1152/ajpheart.2001.281.3.H1286

25. Yoshikawa Y, Zhang G-X, Obata K, Ohga Y, Matsuyoshi H, Taniguchi S, Takaki M (2010) Cardioprotective effects of a novel calpain inhibitor, SNJ-1945 for reperfusion injury after cardioplegic cardiac arrest. Am J Physiol Heart Circ Physiol 298:H643-H651. https:/doi.org/10.1152/ajphe art.00849.2009

26. Matsubara H, Takaki M, Yasuhara S, Araki J, Suga H (1995) Logistic time constant of isovolumic relaxation pressure-time curve in the canine left ventricle. Better alternative to exponential time constant. Circulation. 92(8):2318-2326

27. Takaki M, Akashi T, Ishioka K, Kikuta A, Matsubara H, Yasuhara S, Fujii W, Suga H (1994) Effects of capsaicin on mechanoenergetics of excised cross-circulated canine left ventricle and coronary artery. J Mol Cell Cardiol 26(9):1227-1239. https://doi.org/10.1006/jmcc.1994.1141

28. Nakajima-Takenaka C, Sakata S, Kato S, Ohga Y, Murata KY, Taniguchi S, Takaki M (2005) Detrimental effects after dobutamine infusion on rat left ventricular function: mechanical work and energetics. Exp Physiol 90(4):635-644

29. Zhang GX, Obata K, Takeshita D, Mitsuyama S, Nakashima T, Kikuta A, Hirabayashi M, Tomita K, Vetter R, Dillmann WH, Takaki M (2012) Evaluation of left ventricular mechanical work and energetics of normal hearts in SERCA2a transgenic rats. J Physiol Sci 62(3):221-231. https://doi.org/10.1007/ s12576-012-0200-4

30. Docherty RJ, Yeats JC, Piper AS (1997) Capsazepine block of voltageactivated calcium channels in adult rat dorsal root ganglion neurones in culture. Br J Pharmacol 121(7):1461-1467. https://doi.org/10.1038/ sj.bjp.0701272

31. Liu L, Simon SA (1997) Capsazepine, a vanilloid receptor antagonist, inhibits nicotinic acetylcholine receptors in rat trigeminal ganglia. Neurosci Lett 228(1):29-32. https://doi.org/10.1016/s0304-3940(97)00358-3

32. Pan HL, Chen SR (2004) Sensing tissue ischemia: another new function for capsaicin receptors? Circulation 110(13):1826-1831. https://doi. org/10.1161/01.CIR.0000142618.20278.7A

33. Watanabe H, Murakami M, Ohba T, Ono K, Ito H (2009) The pathological role of transient receptor potential channels in heart disease. Circ 73(3):419-427. https://doi.org/10.1253/circj.CJ-08-1153 
34. Andrei SR, Sinharoy P, Bratz IN, Damron DS (2016) TRPA1 is functionally co-expressed with TRPV1 in cardiac muscle: co-localization at z-discs, costameres and intercalated discs. Channels (Austin). 10(5):395-409. https:// doi.org/10.1080/19336950.2016.1185579

35. Vostarek F, Svatunkova J, Sedmera D (2016) Acute temperature effects on function of the chick embryonic heart. Acta Physiol (Oxf) 217(4):276-286. https://doi.org/10.1111/apha.12691

36. Mattiazzi A, Kranias EG (2014) The role of CaMKII regulation of phospholamban activity in heart disease. Front Pharmacol 27:5. https://doi. org/10.3389/fphar.2014.00005

37. Wang W, Zhu W, Wang S, Yang D, Crow MT, Xiao RP, Cheng H (2004) Sustained $\beta 1$-adrenergic stimulation modulates cardiac contractility by $\mathrm{Ca}^{2+} /$ calmodulin kinase signaling pathway. Circ Res 95:798-806. https:// doi.org/10.1161/01.RES.0000145361.50017.aa

38. Lu MJ, Chen YS, Huang HS, Ma MC (2014) Hypoxic preconditioning protects rat hearts against ischemia-reperfusion injury via the arachidonate 12-lipoxygenase/transient receptor potential vanilloid 1 pathway. Basic Res Cardiol 109(4):414. https://doi.org/10.1007/s00395-014-0414-0

39. MacDougall LK, Jones LR, Cohen P (1991) Identification of the major protein phosphatases in mammalian cardiac muscle which dephosphorylate phospholamban. Eur J Biochem 196:725-734. https://doi. org/10.1111/j.1432-1033.1991.tb15871.x

40. Lotteau S, Ducreux S, Romestaing C, Legrand C, van Coppenolle F (2013) Characterization of functional TRPV1 channels in the sarcoplasmic reticulum of mouse skeletal muscle. PLoS One. 8(3):e58673. https://doi. org/10.1371/journal.pone.0058673

41. Dogan MD, Patel S, Rudaya AY, Steiner AA, Székely M, Romanovsky AA (2004) Lipopolysaccharide fever is initiated via a capsaicin-sensitive mechanism independent of the subtype-1 vanilloid receptor. $\mathrm{Br} J$ Pharmacol 143(8):1023-1032. https://doi.org/10.1038/sj.bjp.0705977

42. Fujimoto S, Mori M, Tsushima H, Kunimatsu M (2006) Capsaicin induces the relaxation of the Guinea-Pig lleum, which is not mediated by TRPV1, and is Capsazepine-Insensitive. Eur J Pharmacol 530(1-2):144-151. https ://doi.org/10.1016/j.ejphar.2005.11.011

43. Mahmoud ME, Shimizu Y, Shiina T, Nikami H, Dosoky RM, Ahmed MM, Takewaki T (2007) Involvement of a capsaicin-sensitive TRPV1-independent mechanism in lipopolysaccharide-induced fever in chickens. Comp Biochem Physiol A 148(3):578-583. https://doi.org/10.1016/j. cbpa.2007.07.012

44. Sharma SK, Vij AS, Sharma M (2013) Mechanisms and clinical uses of capsaicin. Eur J Pharmacol 720(1-3):55-62. https://doi.org/10.1016/j.ejpha r.2013.10.053

45. Thakre PP, Bellingham MC (2019) Capsaicin causes robust reduction in glycinergic transmission to rat hypoglossal motor neurons via a TRPV1independent mechanism. J Neurophysiol 121(4):1535-1542. https://doi. org/10.1152/jn.00059.2019

46. Bao Z, Dai X, Wang P, Tao Y, Chai D (2019) Capsaicin induces cytotoxicity in human osteosarcoma MG63 cells through TRPV1-dependent and -independent pathways. Cell Cycle 18(12):1379-1392. https://doi. org/10.1080/15384101.2019.1618119

\section{Publisher's Note}

Springer Nature remains neutral with regard to jurisdictional claims in published maps and institutional affiliations.
Ready to submit your research? Choose BMC and benefit from:

- fast, convenient online submission

- thorough peer review by experienced researchers in your field

- rapid publication on acceptance

- support for research data, including large and complex data types

- gold Open Access which fosters wider collaboration and increased citations

- maximum visibility for your research: over 100M website views per year

At BMC, research is always in progress.

Learn more biomedcentral.com/submissions 